\title{
TEXTO E ENUNCIAÇÃO
}

\author{
Eduardo Guimarães
}

RESUMO: Pour l'auteur, la notion de texte, prise hors d'un appareil theórique, est empirique et sans valeur analytique. Par contre, texte en tant que catégorie de la théorie de l'énonciation s'impose à partir de la notion de position-auteur et du rapport que celle-ci entreprend avec l'interdiscours qui se représente dans le texte en tant que texte, en y produisant l'illusion d'évidence empirique, responsable par l'effet d'unité et de finitude.

PALAVRAS-CHAVE: enunciação, acontecimento, posições enunciativas, operação enunciativa, posição-autor, texto, textualidade, interdiscurso.

Há algo que todos sabemos que seja texto? Se há, para que procurar saber o que é texto? Esta necessidade é, na verdade, a atestação de que não há o que seja texto por si (evidência do objeto) ou para todos (consenso para os sujeitos).

Este trabalho, aceitando falar sobre o que é texto, terá dois objetivos. Por um lado, fazer uma análise enunciativa da proposta deste campo como de interesse para os estudos sobre a linguagem. Por outro lado, tentará configurar, se é que isto interessa, o que é texto para uma abordagem enunciativa.

Se o texto é tomado como objeto empírico, ele não é objeto específico de nenhuma disciplina ou ciência. Como objeto empírico, o texto pode ser objeto da lingüística, da psicologia, da antropologia, da história, da filosofia, etc.

Isto é, não há nada que por si e com toda evidência seja texto, independentemente de qualquer consideração teórica. Chamar algo de texto é constituir uma categoria e considerá-la pertinente por alguma razão. Estou de fato dizendo que o caráter inquestionável da existência do que se chama texto é já uma categorização e não o reconhecimento de algo que existe por si.

Deste modo, tomar o texto como algo de que se deve tratar lingüisticamente, discursivamente, enunciativamente, não diz respeito ao fato de que no senso comum se considere a existência do texto como algo que precede qualquer reflexão sobre a linguagem. Isto quer dizer que incluir o texto no campo do objeto-linguagem não é o resultado necessário de se reconhecer no campo do objeto aquilo que incompreensivelmente se tinha esquecido de tratar. 
Se há hoje no ar, principalmente em certas áreas dos estudos da linguagem, o desabafo: enfim chegou-se ao texto, ele não se justifica como formulação teórica, nem metodológica. É um desabafo feito do lugar aprisionado pela ilusão da evidência empírica dos objetos de conhecimento.

Texto tem a ver com a ilusão de evidência ligada ao fato de que há seqüências de linguagem que se caracterizam por ter um princípio e um fim. Esta evidência está ligada ao fato de que, em dadas circunstâncias, começa-se a falar e termina-se, começa-se a escrever e termina-se. Mais que isso, o que se escreve recebe uma encadernação chamada livro, que constitui um objeto físico com limites físicos bem determinados e que hoje tem um valor comercial.

Na memória de um computador, o que é um texto? Faz sentido a noção de texto neste caso? O modo de entrar na memória informática independe do começo e fim destas seqüências tomadas como texto.

A pertinência deste objeto finito texto não diz respeito à seqüência em si, mas à relação desta seqüência com o acontecimento em que ela se dá. Uma seqüência de fala tem sua finitude configurada na relação com uma posição enunciativa no acontecimento de linguagem.

Caberia aqui uma pergunta de caráter histórico-metodológico: por que a palavra texto resiste hoje em tantos campos teóricos? e uma outra: o que do funcionamento da designação nos aprisiona na vertigem empírica? Diria que um certo refluxo positivista, empiricista, dá o traço de uma formação discursiva dominante em certos grupos de lingüistas, e com esta formação se impõe a inevitabilidade empírica do que seria texto. E quanto à segunda pergunta, ela está um tanto ligada à primeira. Na designação, a ilusão de unidade do objeto designado funciona segundo as determinações da dominância de uma formação discursiva.

Por outro lado, a manutenção desta palavra por posições tão diferentes estabelece pela via da linguagem o acordo sobre a pertinência de um campo de interesse de conhecimento. Diferentes posições e disciplinas se valem da instabilidade própria da designação (GUIMARÃES, mimeo) para estabelecer um campo de debate particular. Dá-se que no campo da instabilidade designativa de uma palavra, a injunção ideológica a uma interpretação faz funcionar uma interpretação, no caso a empírica, como o sentido primeiro da palavra (sobre a ideologia como injunção à interpretação ver ORLANDI, 1990).

O que é texto se se considera a enunciação?

A pergunta não pode ser essa porque esta pergunta supõe que há texto por si e que, do ponto de vista da enunciação, se qualifica texto por alguma determinação específica. Fazer esta pergunta é aceitar, sem se dar conta, a interpretação ideológica na formação discursiva empiricista.

Façamos, então, outra pergunta.

Dado um conceito de enunciação, que categorias se devem constituir adequadamente neste campo teórico? Interessaria às abordagens enunciativas o campo que movimenta a disputa em torno de designações da palavra texto?

Comecemos por dizer como tratamos a enunciação. Como vimos fazendo 
há algum tempo ${ }^{1}$, a enunciação deve ser tratada como acontecimento histórico. Deste modo, a definimos como um acontecimento de linguagem perpassado pelo interdiscurso, que se dá como espaço de memória no acontecimento. É um acontecimento que se dá porque a língua funciona ao ser afetada pelo interdiscurso. Ou seja, a língua funciona na medida em que um indivíduo ocupa uma posição de sujeito no discurso, e isso, por si só, põe a língua em funcionamento, por afetá-la pelo interdiscurso. A enunciação, deste modo, não diz respeito à situação. E, por ser assim afetada pelo interdiscurso, a enunciação não é homogênea, é uma dispersão que a relação com o interdiscurso produz.

Considerando que uma categoria como texto interessa a uma abordagem enunciativa, vejamos como o interdiscurso se apresenta no texto, como texto. $\mathrm{O}$ interdiscurso aparece como finitude no acontecimento enunciativo em virtude das posições enunciativas aí configuradas. Ou seja, uma posição enunciativa recorta o interdiscurso que se dá, então, no acontecimento, como algo que começa e termina. Deste modo, a textualidade não diz respeito ao falante, ao sujeito falante, ser físico. Diria respeito, por exemplo, em termos das categorias de Ducrot (1984), ao locutorL.

Para mim (v. ORLANDI \& GUIMARÃES, 1988), diz respeito à posiçãoautor. Esta posição assume como suas as palavras que de direito são do interdiscurso. E a condição para assumi-las é que elas se dão ao autor no acontecimento, que se mostra como singular, esquecendo o que de memória constrói o acontecimento, e portanto o texto. Esta é a operação enunciativa fundamental para a textualidade: construir como unidade o que é disperso; produzir a ilusão ${ }^{2}$ de um presente sem memória. E por isso o texto está inapelavelmente aberto à interpretação, que percorre as linhas da dispersão, da memória. (Sobre as questões de autoria e interpretação ver ORLANDI, 1992). E o texto, tal como a enunciação, não diz respeito à situação. A situação como entidade empírica não organiza nada no texto.

Todas as chamadas operações próprias da textualidade e todos os procedimentos que funcionam para estas operações, são processos da construção da ilusão de unidade.

Vou considerar aqui dois funcionamentos próprios da textualidade: coesão e consistência. $\mathrm{A}$ coesão ${ }^{3}$ diz respeito às relações que reenviam a interpretação de uma forma à de outra, numa seqüência do texto. A consistência diz respeito às relações que reenviam a interpretação de uma forma ao acontecimento enunciativo.

Estamos aqui descartando a noção de coerência porque se a tomarmos estaremos considerando que o que caracteriza o que é próprio do acontecimento é algo cognitivo. Estaríamos considerando que um texto se organiza por expressar adequadamente as relações próprias da mente, independentemente de qualquer

\footnotetext{
${ }^{1}$ Ver, por exemplo, GUIMARAES (1993).

${ }^{2}$ Ilusão diz respeito ao imaginário.

${ }^{3}$ Embora utilizando de modo um tanto diferente o conceito de coesão, não se pode deixar de referir aqui Halliday \& Hasan (1976).
} 
historicidade.

Para melhor caracterizar coesão e consistência, esboço a seguir como se poderia tratar aspectos até aqui descritos como anáfora, de um lado, e referência ou dêixis, de outro. Para isto, retomo aqui uma análise feita em "Os Sentidos de Cidadão no Império e na República no Brasil” (GUIMARÃES, 1992).

$\mathrm{O}$ artigo $6^{\circ}$ e seu item $1^{\circ}$, da constituição do Império no Brasil, diz o seguinte:

Art. $6^{\circ}$ - São cidadãos brasileiros:

$1^{\circ}$ - Os que no Brasil tiverem nascido, quer sejam ingênuos ou libertos, ainda que o pai seja estrangeiro, uma vez que este não resida por serviço de sua nação.

Para interpretar o os (neste caso, sinônimo de aqueles) que inicia o item $1^{\circ}$, podemos considerar duas leituras. Uma em que o os é interpretado anaforicamente e outra em que é interpretado como dêitico (mais especificamente como referencial). Ou seja, o os para ser interpretado deve ser remetido ou a uma forma do caput do artigo sexto ou ao acontecimento. Vejamos.

Pela interpretação anafórica, o os seria interpretado como anáfora de quê? Não pode ser de cidadãos brasileiros, pois assim se teria como paráfrase do caput do artigo $6^{\circ}$ e seu item $1^{\circ}$ : "São cidadãos brasileiros: os cidadãos brasileiros que no Brasil tiverem nascido". O os é anáfora de cidadãos. Isto leva à seguinte paráfrase: "São cidadãos brasileiros: os cidadãos ${ }^{4}$ que no Brasil tiverem nascido". Interessa, inclusive, ressaltar que a anáfora estabelece um modo de interpretação que desfaz a determinação. Isto diz respeito ao funcionamento coesivo. Vê-se que, neste caso, esta operação, que parece se dar no nível da amarração da superfície da sequiência textual, produz uma desarticulação da relação de determinação e traz para o texto a sua relação com algo de fora dele. O que é cidadão? Em nenhum momento o texto da constituição do Império do Brasil responde a esta pergunta. Ou seja, aquilo que cidadão designa é dado como conhecido, como anterior ao texto. A resposta a esta pergunta só se encontra, então, se se levar em conta a presença do interdiscurso. Isto é, significar a categoria do cidadão pela anáfora é constituir um efeito de préconstruído ${ }^{5}$ como se houvesse cidadãos com tais e tais predicados, qualidades e que, se nascidos no Brasil, seriam cidadãos brasileiros. A ilusão específica do processo coesivo é a da montagem da unidade interna, própria a uma seqüência homogênea que começa e termina. Este efeito de unidade opera pelo esquecimento de que o que se dá como texto só se interpreta levando em conta o que vem de fora, o interdiscurso. Portanto o que se dá como homogêneo e finito não o é.

Consideremos agora a interpretação dêitica para o os. Neste caso, ele é interpretado como paráfrase de os que não são estes, não são esses. A que a generalidade deste $o s$ (aqueles) refere? Pode-se interpretar o os como referindo-se a algo que indivíduos, pessoas referiria. Por esta interpretação, o caput do artigo $6^{\circ} \mathrm{e}$

\footnotetext{
${ }^{4} \mathrm{O}$ os, agora como elemento dos sintagmas os cidadãos brasileiros e os cidadãos, é um determinante (artigo).

${ }^{5}$ Sobre os efeitos de pré-construído e de sustentação ver, por exemplo, PÊCHEUX (1975, edição brasileira de 1988, p.1 10-111).

68
} 
seu item $1^{\circ}$ seria paráfrase de "São cidadãos brasileiros os indivíduos que no Brasil tiverem nascido [...]". Ou seja, para esta interpretação faz-se necessário considerar o presente do acontecimento, considerar algo referido a partir deste presente. Mas, necessariamente, se apresenta, também, a relação com o interdiscurso. O os será interpretado por uma relação com um interdiscurso em que a categoria do cidadão equivale à categoria da pessoa. Ou seja, o funcionamento da consistência também traz para o texto algo que está fora dele. Não falo aqui de um objeto como referente existente por si. Falo de um objeto que se apresenta pela presença do interdiscurso. A ilusão, neste caso, é a de que aquilo a que um texto reenvia são objetos de um mundo sem história.

A coesão e a consistência são procedimentos do presente do acontecimento. São procedimentos postos em funcionamento como marca da presença de uma posição de autor. São, então, processos que suturam as distâncias, as diferentes posições próprias dos recortes interdiscursivos de um texto. E, nesta medida, a textualidade é um contraponto ao interdiscurso.

A coesão e a consistência são o lugar do presente como tempo da ilusão de unidade. A memória é o tempo da dispersão, do heterogêneo, do múltiplo. Mas não há presente sem memória. A memória é o ancoradouro do presente. O heterogêneo, o disperso, o múltiplo habitam a unidade, o homogêneo, e a unidade do corpo que fala se divide.

\section{BIBLIOGRAFIA}

GUIMARÃES, E. Independência e Morte. Discurso Fundador. Campinas, Pontes, 1993.

GUIMARÃES, E. Os sentidos de cidadão no Império e na República no Brasil. Signo e Seña, Universidade de Buenos Aires, 1992.

GUIMARÃES, E. Enunciação e processos de enunciação. (mimeo).

HALLIDAY, M.A.K.; HASAN, R. Cohesion in English. Longman, 1976.

ORLANDI, E. P. Terra à vista. São Paulo/Campinas, Cortez/Editora da Unicamp, 1990.

ORLANDI, E. P. Autoria e interpretação. In: ENCONTRO DE PSICANÁLISE, São Paulo, PUC, 1992.

ORLANDI, E. P.; GUIMARÃES. Unidade e dispersão: uma questão do texto e do sujeito. Cadernos PUC, São Paulo, EDUC, n.31, 1988.

PÊCHEUX, M. (1975). Semântica e discurso. Campinas, Editora da Unicamp, 1988. 
